\title{
Colorectal Cancer Screening-Who, How, and When?
}

\author{
Roisin Bevan ${ }^{1}$ and Matthew D Rutter ${ }^{1,2}$ \\ ${ }^{1}$ Department of Gastroenterology, University Hospital of North Tees, Stockton-on-Tees, ${ }^{2}$ School of Medicine, Pharmacy and Health, Durham \\ University, Durham, UK
}

Colorectal cancer (CRC) is the third most common cancer worldwide. It is amenable to screening as it occurs in premalignant, latent, early, and curable stages. PubMed, Cochrane Database of Systematic Reviews, and national and international CRC screening guidelines were searched for CRC screening methods, populations, and timing. CRC screening can use direct or indirect tests, delivered opportunistically or via organized programs. Most CRCs are diagnosed after 60 years of age; most screening programs apply to individuals 50-75 years of age. Screening may reduce disease-specific mortality by detecting CRC in earlier stages, and CRC incidence by detecting premalignant polyps, which can subsequently be removed. In randomized controlled trials (RCTs) guaiac fecal occult blood testing (gFOBt) was found to reduce CRC mortality by 13\%-33\%. Fecal immunochemical testing (FIT) has no RCT data comparing it to no screening, but is superior to gFOBt. Flexible sigmoidoscopy (FS) trials demonstrated an 18\% reduction in CRC incidence and a $28 \%$ reduction in CRC mortality. Currently, RCT evidence for colonoscopy screening is scarce. Although not yet corroborated by RCTs, it is likely that colonoscopy is the best screening modality for an individual. From a population perspective, organized programs are superior to opportunistic screening. However, no nation can offer organized population-wide colonoscopy screening. Thus, organized programs using cheaper modalities, such as FS/FIT, can be tailored to budget and capacity. Clin Endosc 2018;51:37-49

Key Words: Colorectal neoplasms; Screening; Colonoscopy

\section{INTRODUCTION}

Colorectal cancer (CRC) is a worldwide problem, with over 1.3 million new cases and almost 700,000 associated deaths reported per year. ${ }^{1}$ The rates of CRC are higher in Westernized countries; ${ }^{2}$ in the UK and America, it is the third most frequently diagnosed cancer, after lung and prostate cancer in men, and lung and breast cancer in women. ${ }^{3,4}$ The lifetime risk of CRC is around 5\%, although there is slight variation between men and women: CRC affects 1 in 14 men and 1 in 19 women in the UK. ${ }^{5}$ The incidence of CRC has been increasing in recent years, ${ }^{6}$ in part because of an ageing population. The CRC incidence increases with age, with most cases

Received: September 5, 2017 Accepted: October 20, 2017

Correspondence: Roisin Bevan

Department of Gastroenterology, University Hospital of North Tees, Hardwick Road, Hardwick, Stockton-on-Tees TS19 8PE, UK

Tel: +44-1642- 617617, Fax: +44-1642-617617, E-mail: roisin.bevan@nth.nhs.uk

(cc) This is an Open Access article distributed under the terms of the Creative Commons Attribution Non-Commercial License (http://creativecommons.org/ licenses/by-nc/3.0) which permits unrestricted non-commercial use, distribution, and reproduction in any medium, provided the original work is properly cited. being diagnosed in people over 60 years. ${ }^{5}$ The recent increase in its incidence may also in part be because of increased availability and use of diagnostic tests for early diagnosis of CRC. This has been observed in the UK, where the CRC incidence increased after the introduction of several national programs designed to increase the rate of early diagnosis. ${ }^{7}$ This shortterm increase should be followed by a drop in CRC incidence, as fewer patients present at a later stage and cancers are prevented by premalignant polyp resection. Again, this has been observed in the UK and may explain the decline in incidence witnessed recently in America. ${ }^{8,9}$

The World Health Organization issued guidelines on screening tests in $1968 .{ }^{10}$ CRC meets these screening requirements: it is a significant worldwide issue, has a latent phase during which treatment is possible and potentially curative, tests to identify it are widely available and accessible to the public, and the natural history of the disease is reasonably well known. There is also a treatable premalignant stage in the development of CRC: adenomatous or serrated polyps harbor the potential to develop malignant changes. Screening should be conducted at a time when the benefits of detecting cancers 
or removing pre-malignant polyps outweigh the potential risks from the screening test.

Screening can be in the form of direct endoscopic or radiological procedures or indirect measures such as stool testing. The approach to developing screening programs differs around the world and is primarily driven by cost and resource constraints, such as endoscopy unit capacity. In some countries, screening is performed as part of routine clinical services, whereas in others, a separate service for screening exists, often with more robust quality assurance. Screening may also be offered as part of an organized program of population invitation or on an opportunistic basis.

In this Review article, we summarized the methods of CRC screening (those currently in use and those with future potential), discussed the populations in which screening may be carried out, and considered when screening should be undertaken. A literature search was performed in PubMed using the following search terms: colorectal cancer screening, guaiac fecal occult blood testing, FIT, stool DNA testing, flexible sigmoidoscopy screening, CT colonography screening, capsule endoscopy screening. National and international guidelines on CRC screening were examined. Further, the Cochrane Database of Systematic Reviews was searched using the term "colorectal cancer screening".

\section{WHO SHOULD BE SCREENED?}

Screening can be targeted at those predisposed to CRC or can be population based for those at average risk. The latter is usually performed after a defined age, given that age is one of the main risk factors for CRC. This review focuses on asymptomatic population-based screening.

\section{Population screening}

There are two, often overlapping, approaches to population-based CRC screening: (1) To detect CRC at an earlier and more treatable stage, thereby reducing CRC mortality; (2) To detect and remove premalignant precursor polyps to prevent CRC development, thereby reducing CRC incidence.

The majority of CRCs develop through the adenoma-carcinoma sequence, ${ }^{11}$ with small adenomas slowly increasing in size over a prolonged period of time, and if these dysplastic polyps accumulate genetic alterations, such as p53 or K-ras mutations, they ultimately develop into CRC. ${ }^{12}$ A similar and increasingly recognized route is the serrated polyp pathway, which may account for up to $35 \%$ of CRCs. ${ }^{13}$ These processes are usually clinically silent-symptoms attributable to CRC do not usually develop until the cancer is advanced, by which time it is less likely to be curable. In England, where the stage at diagnosis was known in $82 \%$ of CRC diagnoses in 2013 , $37 \%$ presented at stage I/II. ${ }^{14}$ The 5-year survival exceeds $90 \%$ for localized disease, but that for disease that has already metastasized is less than $7 \%{ }^{15}$

Screening programs based on premalignant precursor polyp detection, such as flexible sigmoidoscopy (FS) screening, aim to improve CRC mortality by reducing CRC incidence. As this requires the detection of premalignant lesions earlier in the adenoma-carcinoma sequence, screening should occur at an earlier point, because of which screening with this type of program begins at a younger age.

Screening may be offered via an organized screening program, for example, by the Bowel Cancer Screening Programme (BCSP) in England, where individuals aged 55 years are invited for a one-off FS, followed by biennial guaiac fecal occult blood testing (gFOBt) between the ages of 60 and 74 years, or the French, Scottish or Croatian screening programs of biennial gFOBt from ages 50 to 74 years. This approach requires a highly structured program with robust invitation, delivery, follow-up, and data collection methods. These large-scale programs often involve a compromise in terms of screening modality, since the test must be feasible and affordable for whole-population screening and yet, they may save more lives simply because of the greater participation.

An alternative approach is for CRC screening to be opportunistically offered, as it is in America, where guidelines on screening exist, ${ }^{16}$ but an organized program in which participants from across the nation are invited does not. In this model, access to CRC screening depends on public awareness and motivation, access to healthcare providers, and the ability to pay. Participants may derive greater personal benefit as they undergo a more sensitive test (with colonoscopy being the usual screening modality in opportunistic CRC screening), yet the population-wide benefit may be lower because of lower levels of participation. ${ }^{17}$

\section{At-risk groups}

Screening for CRC is also recommended in certain cohorts that carry an increased risk of developing CRC. These include individuals with polyposis syndromes, acromegaly, and colonic inflammatory bowel disease; those with a genetic predisposition such as Lynch syndrome; and those with a family history of CRC. In the present study, we focus on screening asymptomatic populations rather than at-risk groups, but for completeness, the British and American recommendations are listed in Table $1 .^{18-20}$ These groups are offered screening with colonoscopy in most instances, because of its superior sensitivity and specificity. 
Table 1. High-Risk CRC Screening Guidance

\begin{tabular}{|c|c|c|c|}
\hline \multirow{2}{*}{ Condition } & & \multicolumn{2}{|c|}{ Guidance } \\
\hline & & British $^{18}$ & American $^{19,20}$ \\
\hline \multirow[t]{2}{*}{ Family History } & HNPCC & $\begin{array}{l}\text { Colonoscopy at least biennially from } \\
\text { age } 25 \text {, until age } 70-75 \text { or deemed } \\
\text { inappropriate due to co-morbidity }\end{array}$ & $\begin{array}{l}\text { Genetic testing of tumours. If } \\
\text { positive genetic testing, } 2 \text {-yearly } \\
\text { colonoscopy from age } 20-25 \text { to } 40 \text {, } \\
\text { then yearly thereafter }\end{array}$ \\
\hline & $\begin{array}{l}\text { First degree relative with CRC/AA } \\
<50 \text { yr, or } 2 \text { first degree relatives } \\
\text { with CRC/AA }\end{array}$ & $\begin{array}{l}\text { Screening coordinated via genetics } \\
\text { services }\end{array}$ & $\begin{array}{l}5 \text {-yearly colonoscopy starting at age } \\
40 \text {, or } 10 \text { years younger than the age } \\
\text { at diagnosis of the youngest affected } \\
\text { relative }\end{array}$ \\
\hline \multirow[t]{2}{*}{ IBD } & UC or Crohn's colitis & $\begin{array}{l}\text { Screening colonoscopy after } 10 \text { years } \\
\text { Subsequent interval ( } 1-5 \mathrm{yr}) \text { depen- } \\
\text { dent on findings }\end{array}$ & $\begin{array}{l}\text { Pancolitis: } 8-20 \text { years from diagno- } \\
\text { sis-2-3-yearly colonoscopy, then } \\
\text { yearly } \\
\text { Left-sided colitis: } 15-20 \text { years from } \\
\text { diagnosis-2-3-yearly colonosco- } \\
\text { py, then yearly }\end{array}$ \\
\hline & UC with PSC & Yearly colonoscopy & Screening from time of diagnosis \\
\hline \multirow[t]{4}{*}{ Other groups } & Acromegaly & $\begin{array}{l}\text { Screening commences age } 40 \text {. Inter- } \\
\text { val ( } 3 \text { yr or } 5-10 \mathrm{yr}) \text { dependent on } \\
\text { findings }\end{array}$ & \\
\hline & FAP/polyposis syndromes & $\begin{array}{l}\text { FAP: Annual flexible sigmoidoscopy } \\
\text { and alternating colonoscopy from } \\
\text { diagnosis until colectomy indicated } \\
\text { MUTYH-associated polyposis: colo- } \\
\text { noscopy 2-3 yearly from age } 25\end{array}$ & $\begin{array}{l}\text { Those with FAP or at risk of FAP- } \\
\text { yearly flexible sigmoidoscopy or } \\
\text { colonoscopy until colectomy. Post } \\
\text { surgical surveillance depends on } \\
\text { polyp burden }\end{array}$ \\
\hline & Uterosigmoidostomy & Yearly flexible sigmoidoscopy & - \\
\hline & Peutz-Jeghers Syndrome & Colonoscopy biennially from age 25 & - \\
\hline
\end{tabular}

CRC, colorectal cancer; HNPCC, hereditary non-polyposis colorectal cancer; IBD, inflammatory bowel disease; AA, advanced adenomas; UC, ulcerative colitis; PSC, primary sclerosing cholangitis; FAP, familial adenomatous polyposis.

\section{HOW SHOULD WE SCREEN?}

Several methods are available for CRC screening, including indirect tests such as stool testing and direct methods such as lower gastrointestinal (GI) tract endoscopy or radiological investigations. In this section, we review the methods of CRC screening and discuss their accuracy and acceptability.

\section{Stool testing}

Stool testing is used to detect indicators of CRC, usually blood in the stool, and therefore is used in screening where early detection of CRC is the primary aim.

\section{Guaiac fecal occult blood testing}

As CRCs increase in size, they may bleed. Bleeding is often occult and may be intermittent. gFOBt identifies the presence of heme in stool and hence, may detect bleeding from a CRC. In this test, stool is placed on guaiac-impregnated paper; in the presence of heme, a peroxidase reaction occurs, causing the paper to turn blue. This is a qualitative assessment, that is, the test reader must decide whether or not the color change is adequate. Patients who are deemed gFOB-positive are subsequently referred for a diagnostic colonic investigation, usually colonoscopy.

To account for the potentially intermittent nature of CRC bleeding, stool sampling is usually required from several separate stool samples. The test is also not specific to human blood: any heme present in the stool sample can interact with the guaiac, including non-human heme in ingested red meat. Foods with naturally high levels of peroxidase (such as horseradish, broccoli, cauliflower, or cantaloupe) can also cause a positive reaction. ${ }^{21}$ Dietary modifications may reduce the false positive rate, but this is at the expense of reduced participation due to the added complexity. Testing can be performed on rehydrated (more sensitive, less specific) or non-rehydrated samples (less sensitive, more specific). gFOBt is also limited by its poor sensitivity for detection of adenomas and CRC compared to other screening modalities, ${ }^{17}$ although its availability, lower cost than immunochemical tests, established use, and randomized controlled trial (RCT) evidence base demonstrat- 
ing its effectiveness in reducing CRC mortality have led to it being the most frequently used fecal occult blood test in early CRC screening studies. In contrast, no RCTs have been conducted for fecal immunochemical testing (FIT) thus far. ${ }^{22}$

A meta-analysis of three trials of biennial gFOBt including over 172,000 people demonstrated a relative reduction in CRC mortality by $15 \% .{ }^{23}$ Four large-scale trials have examined gFOBt as a screening tool for CRC, showing positivity rates of $0.8 \%-5.3 \%$ for non-rehydrated samples and $1.7 \%-14.3 \%$ for rehydrated samples (Table 2). ${ }^{24-27}$ The English BCSP currently uses non-rehydrated samples for the gFOBt and previously demonstrated a positivity rate of $2 \% \cdot{ }^{15,28}$ A similar rate has been also shown in Scotland (2.1\% positivity; age of screened individuals, 50-69 years) and France (2.8\% positivity; age of screened individuals, 50-74 years), ${ }^{29}$ and a higher positivity rate of 3.6\% was observed in Finland (age of screened individuals, 60-69 years; ${ }^{30}$ an earlier study in Finland with 60to 64-year-old individuals reported a gFOBt positivity of $2.1 \%){ }^{31}$ However, the rate of CRC diagnosis after a positive gFOBt varies between 7\% and 21\% in England, Scotland, and France, ${ }^{28,29,32}$ but is only $3.6 \%$ in Finland. ${ }^{33}$ A similar low CRC detection after a positive gFOBt was observed in Croatia (6.8\% positivity; CRC incidence after positive gFOBt, $3.8 \%),{ }^{34}$ but uptake of this program was low, at less than $20 \%$. These programs and their outcomes are summarized in Table 3. It should be noted that the definition of test positivity differs from program to program. In England, double sampling is required from 3 separate stools, and a positive test is defined as 5 or 6 of 6 windows being positive for heme. A repeat kit is requested for 1-4 positive windows; if any window is positive in the repeat test, the findings are deemed positive. If no windows are positive in the repeat kit, a third kit is performed; if any window is positive in that kit, the participant is deemed to have a positive result. If no windows are positive in the third kit, the participant is deemed to have had a negative test. ${ }^{35} \mathrm{In}$ both the French and Finnish programs, a test is deemed positive if any of the 6 windows are positive for heme. ${ }^{29,30}$ In the three previously described trials of biennial gFOBt screening as well, the definition of positivity differed: the Nottingham study required 5 or 6 positive windows, or 1-4 positive windows followed by 1-6 positive windows in a repeat test, ${ }^{24}$ and both the Minnesota and Funen studies deemed 1-6 windows positive for heme as a positive test. ${ }^{25,26}$

When compared against FS screening (with the expectation that positive gFOBt results would lead to colonoscopy as would FS that identified adenomas) in a Cochrane review, both gFOBt and FS screening were found to reduce CRC mortality when compared to no screening at all (FS: RR, 0.72 [95\% confidence interval [CI], 0.65-0.79]; gFOBt: RR, 0.86 [95\% CI, 0.80-0.92]), but no conclusion could be reached as to

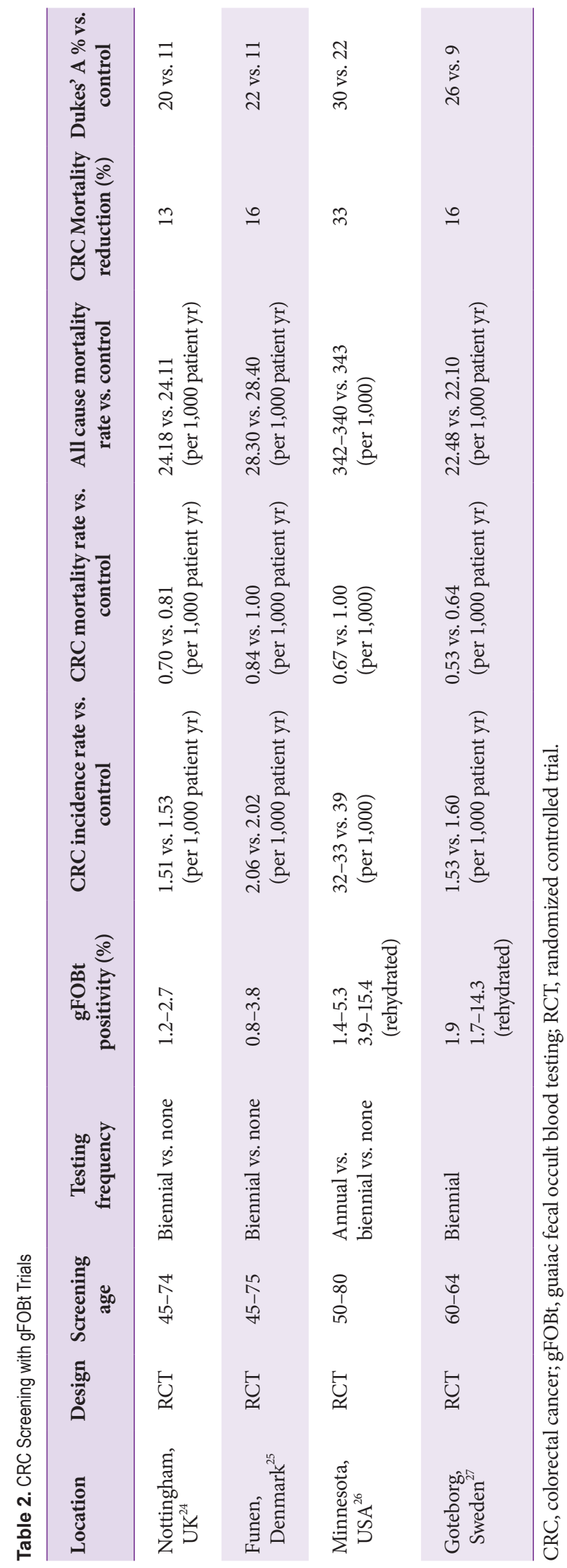




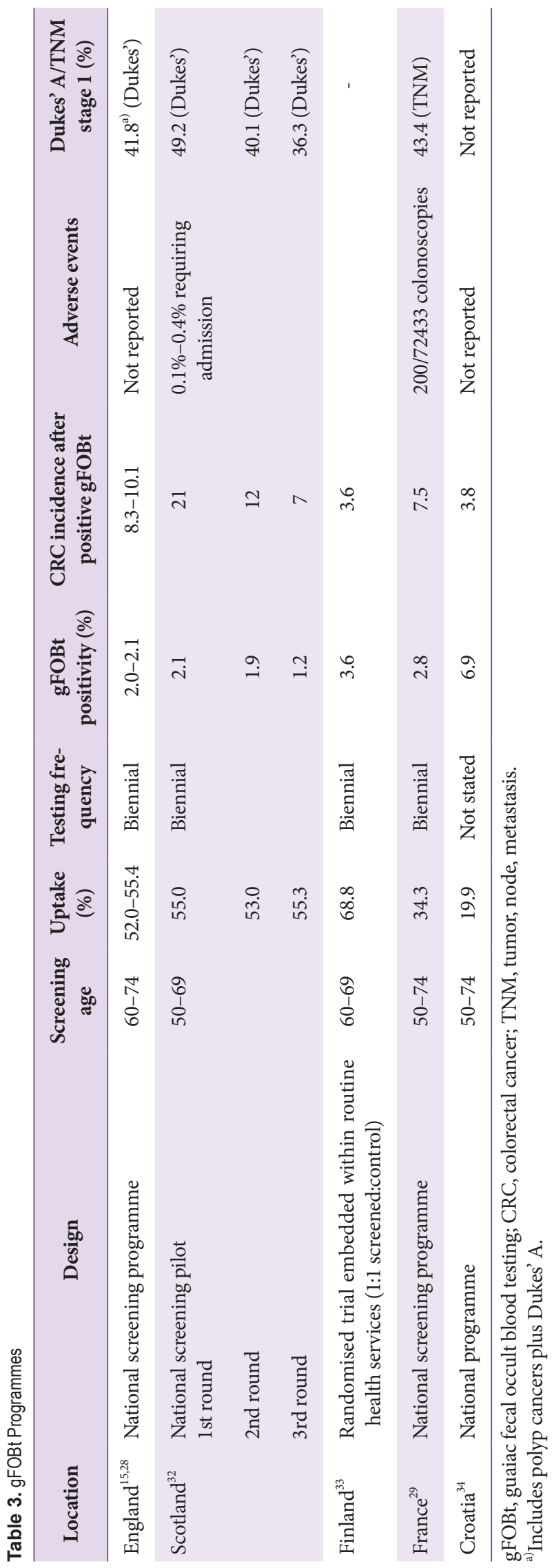

whether one method was better than the other because only low quality data were available. ${ }^{36}$ However, as gFOBt has been shown to have a lower sensitivity for detection of advanced adenomas ( $11 \%-41 \%$ compared to $50 \%-81 \%$ for FS), it is probably less effective at reducing CRC incidence. ${ }^{37}$

Five countries have an established, fully rolled-out gFOBtbased screening program. Uptake of screening in these countries is $68.8 \%$ in Finland (although the programme is being implemented via a randomized trial), ${ }^{30} 55.4 \%$ in the $\mathrm{UK}^{15}$ $53 \%-55.3 \%$ in Scotland, ${ }^{32} 34.4 \%$ in France, ${ }^{29}$ and $19.9 \%$ in Croatia. ${ }^{34}$ Many factors play a part in the reasons for non-participation in screening, including socioeconomic status, ethnicity, age, and gender. ${ }^{38}$ The nature of the test procedure itself has also been reported as a reason for non-participation in CRC screening: ${ }^{39,40}$ this is one of the reasons that many gFOBtbased programs are moving to FIT-based screening.

\section{Fecal immunohostochemical testing}

FIT analyzes stool samples for the presence of blood using a mono- or polyclonal antibody to human hemoglobin. When hemoglobin is present, it forms a complex with the antibody, which can be quantified. ${ }^{41}$ FIT has several advantages over gFOBt. Unlike gFOBt, it is not affected by false positive results from food, as it is specific for human hemoglobin. FIT requires fewer sampling episodes, often with only one sample being required. ${ }^{42}$ It is also more specific for a lower GI source of bleeding than gFOBt is. ${ }^{22}$ A meta-analysis of FIT accuracy demonstrated that its overall pooled sensitivity for CRC is 0.79 (95\% CI, 0.69-0.86) and specificity is 0.94 (95\% CI, 0.92-0.95). ${ }^{43}$ Further, the advanced adenoma yield over two rounds of screening did not differ irrespective of whether 1 or 2 samples were taken at each screening round, suggesting that single sample testing is adequate. ${ }^{44}$

As it allows quantitative analysis of stool blood content, FIT has varied cut-off levels for detection, and the analysis process is automated. Review of the existing literature demonstrated a decreased positivity rate and increased specificity and positive predictive value for CRC and advanced adenomas with increasing cut-off levels. ${ }^{22}$ Frequently used cut-off points are 20, 50, and $100 \mu \mathrm{g} / \mathrm{g}\left(100,250\right.$, and $400 \mathrm{ng} / \mathrm{mL}$ respectively). ${ }^{43}$ This ability to vary the "positive test" cut-off allows screening programs to adjust the level to provide an acceptable threshold for further investigations without exceeding the capacity of the endoscopy service, which will deliver those investigations. In established gFOBt programs, a FIT cut-off to provide the same positivity rate as for gFOBt may be used: for example, in Scotland, a cut-off of $80 \mu \mathrm{g} / \mathrm{g}(400 \mathrm{ng} / \mathrm{mL})$ provided approximately the same positivity level as gFOBt of $2.4 \% .{ }^{42}$ An alternative approach was used in a Dutch study where they aimed to detect the same amount of advanced adenoma using 
FIT as with gFOBt. They found a cut-off of $75 \mathrm{ng} / \mathrm{mL}$ lead to a similar rate of advanced adenomas as the gFOBt program. ${ }^{45}$ Consideration has also been given to the use of a lower cutoff level, with a resulting higher positivity and consequently, higher CRC and advanced adenoma detection rates (ADRs). It was demonstrated that a lower cut-off could allow extension of the screening interval as positivity rates and CRC and advanced ADRs were similar to those in the standard screening scenario. ${ }^{46}$ It has been recommended that standardization of FIT reporting is required if it is to become a routine part of CRC screening. ${ }^{47}$

FIT is in use in a number of screening programs, many of which are still in the pilot or roll-out phases. ${ }^{17}$ Few have yet reported outcomes of screening with FIT outside of a trial setting. There are no trials comparing the outcomes of screening with FIT versus no screening, but comparisons of FIT versus gFOBt have been reported. All available outcomes of FIT are summarized in Table $4{ }^{42,48-50}$ Patient compliance and satisfaction with FIT have been shown to be greater than with those with gFOBt. The participation rate was reported to be $12 \%$ higher for FIT than $\mathrm{gFOBt},{ }^{49}$ even when dietary restrictions for the gFOBt arm were lifted. This suggested the simpler method and requirement for only a single sampling episode rather than 3 episodes affected the likelihood of completing the screening process.

\section{Other stool tests}

Stool DNA testing is a developing area of investigation. Stool samples are analyzed for DNA markers of neoplasia, since the cells of CRCs and advanced adenomas contain abnormal DNA markers (such as aberrantly methylated promoter regions, mutant $\mathrm{K}$-ras, and $\beta$-actin). ${ }^{51}$ Early stool DNA tests detected only one marker, but newer tests are multi-target and have demonstrated higher sensitivity than FIT for advanced adenomas ( $42 \%$ vs. $23 \%$ ) and CRC ( $92 \%$ vs. $72 \%){ }^{51}$ However, this improved sensitivity comes at the expense of higher test positivity ( $16 \%$ vs. $7 \%$, for FIT) and will therefore place greater demands on endoscopy services. ${ }^{51}$

Other stool tests such as those for RNA markers, protein markers, and microbiome-based biomarkers are also being investigated for use in CRC screening, but further work is required before these find common usage. Current limitations are related to high costs and practicalities as a large volume of stool is required. ${ }^{51}$

\section{Endoscopy}

Endoscopy can be used to detect asymptomatic CRC, with the aim of shifting the diagnosis towards an earlier stage and thereby reducing CRC mortality. Endoscopy can also detect and remove adenomas, interrupting the adenoma-carcinoma sequence, preventing cancer development and hence reducing $\mathrm{CRC}$ incidence. The latter strategy is the primary rationale underpinning screening with FS.

\section{Flexible sigmoidoscopy}

FS screens for adenomas using a flexible endoscope inserted into the distal colon, with the aim of examining at least the rectum and sigmoid and, if possible, as far as the splenic flexure. There are variations in practice with regard to the bowel cleansing preparation required (enema preparation versus full oral bowel cleansing), depth of insertion desired, medications used (none, Entonox, or intravenous sedation), and the threshold for referral for a completion colonoscopy. There have been four RCTs of FS screening individuals in the age range 55-74 years conducted in Europe $e^{52-54}$ and America. ${ }^{55}$ These are summarized in Table $5{ }^{50,52-57}$ The European studies offered once-only FS, whereas the American study offered subsequent FS after 3-5 years. The primary goal of FS screening, particularly when used toward the lower end of the age range, is to detect and resect premalignant adenomatous polyps, preventing cancer development. Pooled analysis of these studies estimated a risk reduction of $18 \%$ for CRC incidence and $28 \%$ for deaths from CRC. ${ }^{58}$ Further, a more recent pooled analysis of three of these four studies (two of the European studies and the American trial) evaluated the effect of age and gender on CRC incidence and mortality, demonstrating a reduction of $24 \%$ and $33 \%$, respectively, in men regardless of age, but a smaller effect in women, and in women younger than 60 years rather than older than $60 . .^{59}$

Compared to gFOBt or FIT, FS has a higher detection rate

Table 4. FIT Screening Outcomes

\begin{tabular}{|c|c|c|c|c|c|c|c|}
\hline Location, yr & Design & Age & $\begin{array}{l}\text { FIT cut off } \\
(\mathrm{ng} / \mathrm{mL})\end{array}$ & $\begin{array}{c}\text { FIT positivity } \\
(\%)\end{array}$ & $\begin{array}{c}\text { FIT CRC } \\
\text { incidence (\%) }\end{array}$ & $\begin{array}{c}\text { gFOBt positivity } \\
(\%)\end{array}$ & $\begin{array}{c}\text { gFOBt CRC } \\
\text { incidence (\%) }\end{array}$ \\
\hline Netherlands, $2008^{48}$ & RCT_FIT vs. gFOBt & $50-75$ & 100 & 5.5 & 0.2 & 2.4 & 0.1 \\
\hline Netherlands, $2010^{49}$ & RCT_FIT vs. gFOBt vs. FS & $50-74$ & 100 & 4.8 & 0.5 & 2.8 & 0.3 \\
\hline Scotland, $2013^{42}$ & Block evaluation of FIT & $50-74$ & 400 & 2.4 & 0.1 & - & - \\
\hline
\end{tabular}

FIT, fecal immunochemical testing; CRC, colorectal cancer; gFOBt, guaiac fecal occult blood testing; RCT, randomized controlled trial; FS, flexible sigmoidoscopy. 


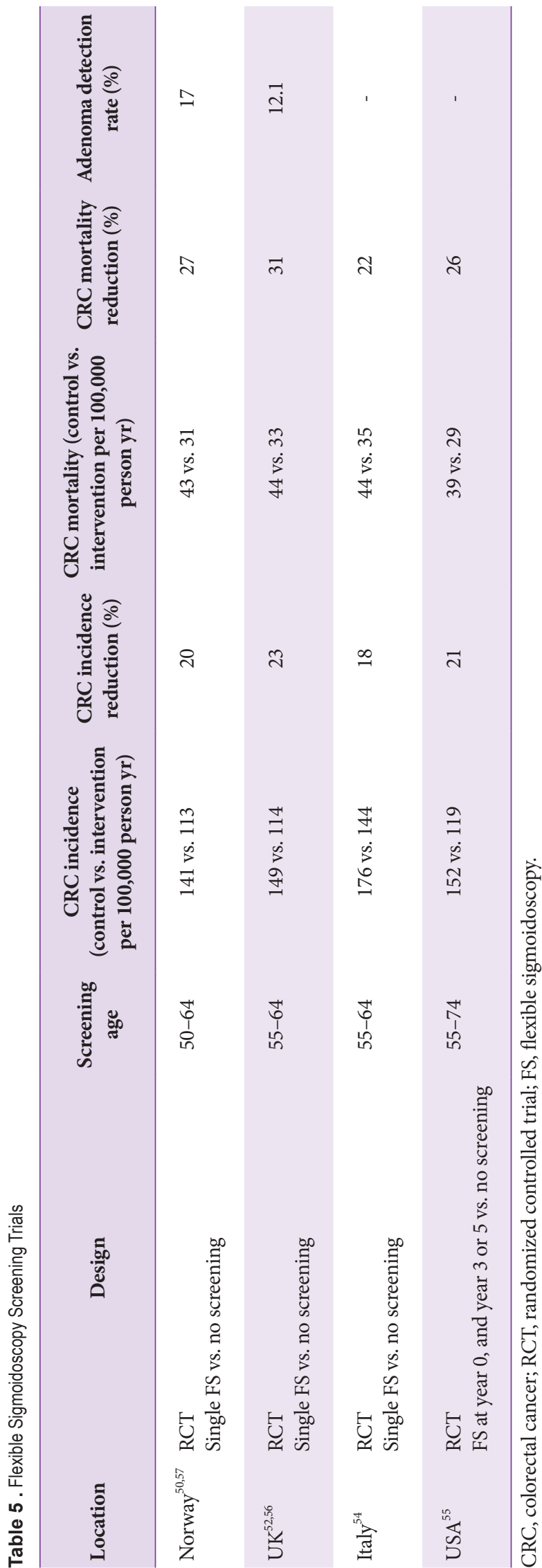

of advanced neoplasia (i.e., advanced adenomas and CRC) ${ }^{49}$ but has a lower specificity and sensitivity than colonoscopy for both advanced adenomas and CRC. ${ }^{37}$

On the basis of the findings from the UK FS screening tri$\mathrm{al},{ }^{52}$ the English BCSP recently added a one-off FS screening for all 55-year-olds. This trial now has 17 years of follow-up data and shows that a single FS results in reduction in CRC incidence and mortality of $26 \%$ and $30 \%$, respectively, in intention-to-treat analyses. ${ }^{60}$ Initial pilot sites commenced in 2013 with roll-out to all screening centers planned by 2018 . An early pilot of the program demonstrated an ADR of $9.8 \%,{ }^{61}$ and first-wave pilot sites have reported similar rates. ${ }^{62}$ This rate initially appears lower than the $12.1 \%$ ADR reported in the UK trial, but two factors affect this figure: first, the population age being screened differs (55-60 years in the study versus 55 years in the screening program) and as already discussed, the ADR increases with age; second, the ADR in the screening program is calculated from histological analysis from the index procedure only, whereas in the trial, a composite ADR was calculated based on adenomas detected at both the screening FS and the subsequent colonoscopy.

A meta-analysis considering survival benefit (i.e., the longterm benefits over several years versus the immediate harms screening exposes participants to) suggested FS may be an appropriate screening test to offer to older adults (when compared to no screening), provided they have a life expectancy of more than 10 years, as the time taken to benefit for an absolute risk reduction of 1 in 1,000 was 9.4 years. ${ }^{63}$ A Cochrane review of FS screening suggested similar effectiveness of gFOBt, but in the absence of any trial data comparing the two screening processes, it could not conclude that one method was better than the other. ${ }^{36}$

FS is deemed to be a low-risk procedure (in the three RCTs of FS screening, there were two perforations in almost 54,000 procedures), ${ }^{56,57,64}$ although subsequent colonoscopy based on initial FS findings carries some additional risk. To date, only England offers an organized national program of FS screening, with a pilot program running in Norway ${ }^{17}$ and some areas of Italy offering FS screening. ${ }^{65}$ Uptake in England was $44.1 \%$ in the first year of the program, with significant variation across the country. ${ }^{62}$ Uptake was lower than in the gFOBt arm of the BCSP, where it approached $60 \%{ }^{66}$ Posttest questionnaires were utilized during the pilot phase of the program, demonstrating overall high levels of satisfaction and low levels of embarrassment. ${ }^{67}$ However, $43 \%$ of the participants reported moderate or severe pain during the procedure, a level underestimated by endoscopists ${ }^{62}$ and suggests a need to evaluate comfort levels further within the program. It is not yet known how experience of this FS program at 55 years of age will affect uptake and involvement in the gFOBt arm of 
screening starting at 60 years of age, nor is it known what the effect of prior FS screening will be on the pathological yield of subsequent FOB/FIT screening.

\section{Colonoscopy}

Examination of the entire colon using a flexible colonoscope is the "gold standard" investigation for CRC. Screening with colonoscopy has the primary aim of detecting CRC and a secondary aim of detecting and removing adenomas. It allows direct assessment of the entire colonic mucosa, although visualization is rarely $100 \%$. A post-colonoscopy CRC (PCCRC, a CRC diagnosed within 3 years of negative colonoscopy) suggests that a cancer or premalignant polyp may have been missed at colonoscopy. A nation-wide study in England demonstrated this occurred at a rate of $8.6 \%,{ }^{68}$ and this should be considered when counseling participants. The PCCRC rate is an important indicator of the quality of colonoscopy, and it has been demonstrated that endoscopists with higher ADR have lower PCCRC rates. ${ }^{69,70}$ As such, ADR is used as a key surrogate marker for colonoscopy quality. Colonoscopy should therefore be of the highest quality to maintain the benefits of screening, and serial audits of practice in the UK have shown improvements in the key performance indicators (KPIs) for diagnostic colonoscopy. ${ }^{9,71}$ In England, BCSP colonoscopies are performed by screening-accredited colonoscopists who maintain high KPI standards. The BCSP and its data collection system have ensured improvements in KPIs and more robust quality assurance. ${ }^{72}$ In other countries, specific screening accreditation is often not required, although the need for high-quality procedures is well recognized.

Colonoscopy is occasionally offered as the initial screening tool of choice in countries where screening is offered opportunistically. Only Poland has an organized screening program with colonoscopy as the primary screening test. This program started as an opportunistic screening program ${ }^{73}$ and has randomized 55- to 64-year-old individuals to an immediate or postponed invitation to screening since 2012. ${ }^{74}$ In America, guidelines recommend colonoscopy screening commencing at age 50 years, with 10 -yearly procedures. ${ }^{16}$ This screening is opportunistic and is offered via the patients' healthcare provider and is not part of an organized program. The American College of Gastroenterology guidelines ${ }^{16}$ suggest a range of alternatives that can be offered depending on patient preference.

Although strong evidence backs the use of endoscopic screening, there is currently little proof that colonoscopy is superior to FS in terms of mortality reduction. Two large-scale RCTs are underway to explore the outcomes of screening colonoscopy ${ }^{75,76}$ but no results are expected until the next decade. Cohort studies of patients undergoing colonoscopy and clearance of polyps demonstrate reduction of CRC incidence by up to $90 \%,{ }^{77,78}$ but these are not asymptomatic populations.

In most countries, colonoscopy is used as the second step in the screening process after FS or fecal occult blood testing (with gFOBt or FIT). ${ }^{17}$ This is primarily because of cost and resource constraints and has been demonstrated to be a cost-effective measure. ${ }^{17,79}$

One of the drawbacks of colonoscopy as a screening tool is the potential for complications. These include bleeding, bowel perforation, complications of sedation, and complications of bowel cleansing preparations. Overall, low rates of serious complications have been reported by the English BCSP (bleeding requiring transfusion, $0.04 \%$; perforation, $0.06 \%$ ) and the French screening program (overall rate of serious complications, $0.06 \%)^{15,28,29,80}$

Colonoscopy can be an uncomfortable procedure, and overall patient experience (taking into account not just discomfort but embarrassment, bloating, and other aspects) should be maintained at an acceptable level to ensure it is a viable screening option. ${ }^{67,72,81,82}$ Work on comfort during screening has been undertaken in the English BCSP, and colonoscopy and FS procedures have been largely well tolerated, with no or minimal pain reported in $64.3 \%$ and $79 \%$ cases, respectively, and severe pain reported in only $1.3 \%$ and $1 \%$, respectively. ${ }^{72.81}$ However, it should be noted that these comfort scores were recorded by the nursing staff, and there appeared to be a discrepancy between these scores and those reported by patients; in qualitative studies, over $25 \%$ of patients reported experiencing more discomfort than expected with both screening modalities. ${ }^{67,83}$

\section{Colon capsule endoscopy}

Examination using colon capsule endoscopy (CCE) allows minimally invasive assessment of the large bowel. Bowel cleansing is required, in similar fashion to colonoscopy, with European guidelines recommending the use of 4 liters of polypethylene glycol for preparation. ${ }^{84}$ Two meta-analyses of CCE showed this procedure had a sensitivity of $71 \%-73 \%$ for detection of all polyps and $68 \%-69 \%$ for significant findings (defined as any polyp of $6 \mathrm{~mm}$ or larger or more than 3 polyps), with a specificity of $75 \%-89 \%$ and $82 \%-86 \%$, respectively. ${ }^{85,86}$ While these findings are comparable to those of other noninvasive measures, concerns have been raised about its accuracy, particularly when bowel preparation is considered; one study showed good or excellent preparation quality in only $52 \%$ of cases, with subsequent higher adenoma and cancer detection at colonoscopy. ${ }^{87}$ It should of course be noted that individuals with lesions detected during CCE require colonoscopy for removal of the identified lesions, as CCE cannot be used to obtain histological samples. It has been shown to be well 
tolerated by patients, ${ }^{88}$ and in areas where CRC screening participation is poor, it has also been shown to improve uptake. ${ }^{89}$ CCE is a potentially attractive modality for CRC screening but is currently limited by availability, expense, and the need for further procedures if lesions are detected, and further research is required before its use becomes commonplace. ${ }^{90}$

\section{Radiology}

Computed tomographic colonography (CTC; virtual colonoscopy) may be used to evaluate the bowel for CRC, either as an initial screening modality or after gFOBt/FIT, in the same way as colonoscopy. It requires bowel cleansing preparation with laxatives, or it can be performed with non-laxative bowel preparation with fecal tagging (wherein oral contrast is consumed and digital image manipulation is performed to provide a CT view of the bowel). Carbon dioxide is insufflated into the bowel using a small rectal catheter. In a multicenter RCT comparing CTC with colonoscopy in symptomatic patients, the detection rate of cancer or large polyps was found to be the same in both arms (11\%). For lesions over $1 \mathrm{~cm}$ in size, CTC performed comparably to colonoscopy, but for smaller lesions, the sensitivity of CTC dropped to $50 \% .{ }^{41}$ CTC has a significantly higher detection rate of CRC and large polyps than that of barium enema, ${ }^{91}$ and barium enemas are consequently no longer considered appropriate for screening. CTC has been shown to be more acceptable to patients than barium enemas are, with greater satisfaction, and less pain, nausea, vomiting, and wind. ${ }^{92}$ When CTC was compared to colonoscopy in a randomized trial, the initial satisfaction was higher with the former, but after longer follow-up and subsequent investigations, individuals who underwent initial colonoscopy were more satisfied. ${ }^{93}$ A meta-analysis suggested that symptomatic patients preferred colonoscopy, as opposed to screening patients, who demonstrated a preference for CTC. ${ }^{94}$

\section{WHEN SHOULD WE SCREEN?}

\section{Lower age limit}

CRC is an age-related disease, with over $80 \%$ of these cancers being diagnosed in individuals over the age of 60 years. ${ }^{4}$ Premalignant adenomatous polyps precede the development of cancer by at least 10 years, on average. The reported prevalence varies from around $10 \%$ of 55 -year-old individuals with adenomas detected in the distal colon ${ }^{56}$ to 1 in 3 people by the age of 60 years with adenomas anywhere in the bowel. ${ }^{95,96}$ Therefore, in most programs, CRC screening in average-risk populations commences around the age of 50-60 years. ${ }^{17}$

When deciding what age group to screen, the potential benefits gained, the potential risks of undergoing screening, and the resources available should be considered. For example, as CRC prevalence increases with age, if resources are limited, maximal cost effectiveness may be obtained by screening an older cohort of patients. However, this must be balanced against the reduced number of life-years gained when screening older people. Modeling packages have been used to balance these factors and analyze the various connotations of screening modalities and age ranges screened. In America, two modeling tools (MISCAN and SimCRC) were initially used in 2009, and the study concluded that screening should take place from 50 years of age with either annual FOBt, 10-yearly colonoscopy, or FOBt every 2-3 years plus 5-yearly FS. ${ }^{96}$ Further analysis was performed in 2016 to include FIT and CTC. It explored the option of earlier onset of screening (at 45 years) in conjunction with a longer screening interval (15-yearly colonoscopy), but the researchers concluded that the minimal number of life-years gained was not justifiable given the lack of evidence to support earlier screening; further, commencing screening at 50 years with 10 -yearly colonoscopy, annual FIT, 10-yearly FS combined with annual FIT, or 5-yearly CTC balanced the risks and benefits against number of life-years gained. ${ }^{97}$ Similar analyses were undertaken in England prior to commencement of the BCSP. ${ }^{95}$

\section{Upper age limit}

In America, the Centers for Disease Control currently recommend screening with colonoscopy up to the age of 75 years, and thereafter on an individual basis. ${ }^{20}$ This guidance is under review at present, with new guidance suggesting those between the ages of 75 and 85 years may be screened based on individual assessment of risk versus benefit, with no further screening over 85 years of age. ${ }^{98}$ In England, gFOBt screening is offered routinely up to age 74 years, with opt-in available after this age. An American study of patients aged 70 years and older and undergoing at least two colonoscopies demonstrated ongoing development of new neoplastic lesions, with cancer rates rising more sharply than advanced adenoma rates. ${ }^{99}$ The authors therefore suggested that colonoscopic screening still had a role for individuals aged over 70 years, but recommended that clinical judgement of co-morbidities and procedural risk be considered at all times; further, those in charge of the screening must acknowledge that new lesions detected may represent lesions missed at prior colonoscopy. ${ }^{99}$ Tang et al. considered this risk in a survival benefit analysis of FS screening. ${ }^{63}$ They suggested a time period of 9.4 years to prevent one death from every 1,000 invited for FS screening and weighed this against the 1 in 1,000 risk of serious complications during FS, concluding that a life expectancy of at least 10 years was required to gain benefit from screening. However, it was also suggested that this benefit depended on previous screening 
exposure, and in those who had never had a screening test or examination of the bowel, the "time to benefit" may be considerably shorter. ${ }^{100}$

\section{Screening frequency}

Most gFOBt programs use a biennial screening strategy. Of the four large trials of FOBt screening, three used biennial screening and one used annual screening. Systematic review of these four trials demonstrated a greater reduction in CRC mortality with annual testing than with biennial testing (33\% vs. $21 \%) .^{23}$ It should be noted that the study that performed annual screening used rehydrated samples, leading to higher positivity rates and subsequently higher numbers of colonoscopies performed, which may have influenced the CRC detection. ${ }^{26}$ Where screening with colonoscopy is offered, the interval is usually 10 yearly ${ }^{17}$ as per the recommendations of the American College of Physicians ${ }^{101}$ and the US Multi-Society Task Force on Colorectal Cancer. ${ }^{102}$ FS is offered as a oneoff, with benefits shown to extend to well over a decade. ${ }^{52}$

\section{CONCLUSIONS}

CRC remains a major cause of mortality worldwide. Its relatively slow natural history and lengthy and eminently treatable premalignant phase make it highly suitable for screening. Screening should be offered to those who are at increased risk of developing CRC because of family history or predisposing conditions but is also cost effective when offered to the asymptomatic population. Several methods for screening are currently available, including stool testing, colonoscopy, FS, and CTC. Other novel methods are under investigation, although their role is as yet undetermined. For an individual, the gold standard for examining the bowel is colonoscopy, and as such, despite no corroborating RCT data, this would be the optimum screening modality. However, on a population level, organized screening programs are preferable to opportunistic screening and therefore, need to be tailored to meet the needs of the population depending on resource availability. Methods such as FIT and FS are affordable, have been shown to be feasible for use in organized programs, and have been shown to reduce CRC incidence and mortality. Simulation models allow analysis of the options available when commencing or changing a screening program, particularly with regard to pressure on services, as resource availability is likely to be the limiting factor for healthcare providers. Although full organized programs are preferable, where these do not exist, CRC screening can still be performed on an opportunistic basis. The screening method used should be of the highest quality, and for endoscopic procedures, KPIs can be used to monitor quality. Established organized screening programs produce high-quality data about their performance and program structure, providing a basis for other screening programs to be developed.

\section{Conflicts of Interest}

The authors have no financial conflicts of interest.

\section{Author Contributions}

Conceptualization: Matthew D Rutter

Formal analysis: Roisin Bevan

Investigation: $\mathrm{RB}$

Writing-original draft: $\mathrm{RB}$

Writing-review\&editing: RB, MDR

\section{REFERENCES}

1. International Agency for Research on Cancer. GLOBOCAN 2012: estimated cancer incidence, mortality and prevalence worldwide in 2012 [Internet]. Lyon: IARC; c2012 [cited 2017 Sep 5]. Available from: http:// globocan.iarc.fr/Default.aspx.

2. Center MM, Jemal A, Smith RA, Ward E. Worldwide variations in colorectal cancer. CA Cancer J Clin 2009;59:366-378.

3. Burt RW, Barthel JS, Dunn KB, et al. NCCN clinical practice guidelines in oncology. Colorectal cancer screening. J Natl Compr Canc Netw 2010;8:8-61.

4. Cancer Research UK. Bowel cancer statistics [Internet]. London: Cancer Research UK; c2015 [cited 2017 Sep 5]. Available from: http://www. cancerresearchuk.org/health-professional/cancer-statistics/statistics-by-cancer-type/bowel-cancer?_ga =2.199557997.216204478. 1517035023-396171367.1516104333\#heading-Zero

5. Cancer Research UK. Bowel cancer incidence statistics [Internet]. London: Cancer Research UK; c2015 [cited 2017 Sep 5]. Available from: http://www.cancerresearchuk.org/health-professional/cancer-statistics/ statistics-by-cancer-type/bowel-cancer/incidence?_ga=2.130656591. 172763994.1517148794-396171367.1516104333\#heading-Eleven.

6. Center MM, Jemal A, Ward E. International trends in colorectal cancer incidence rates. Cancer Epidemiol Biomarkers Prev 2009;18:1688-1694.

7. Valori R, Rutter M, Aravani A, Rashbass J, Vernon S, Morris EJA. National early diagnosis initiatives and their impact on the incidence of colorectal cancer in England. United European Gastroenterol J 2016;4:800-811.

8. Welch HG, Robertson DJ. Colorectal cancer on the decline--why screening can't explain it all. N Engl J Med 2016;374:1605-1607.

9. Gavin DR, Valori RM, Anderson JT, Donnelly MT, Williams JG, Swarbrick ET. The national colonoscopy audit: a nationwide assessment of the quality and safety of colonoscopy in the UK. Gut 2013;62:242-249.

10. Wilson JM, Jungner YG. Principles and practice of mass screening for disease. Bol Oficina Sanit Panam 1968;65:281-393.

11. Leslie A, Carey FA, Pratt NR, Steele RJ. The colorectal adenoma-carcinoma sequence. Br J Surg 2002;89:845-860.

12. Cho KR, Vogelstein B. Genetic alterations in the adenoma--carcinoma sequence. Cancer 1992;70(6 Suppl):1727-1731.

13. Snover DC. Update on the serrated pathway to colorectal carcinoma. Hum Pathol 2011;42:1-10.

14. Cancer Research UK. Cancer incidence for all cancers combined [Internet]. London: Cancer Research UK; c2015 [cited 2017 Sep 5]. Available from: http://www.cancerresearchuk.org/health-professional/cancer-statistics/incidence/all-cancers-combined? ga $=2.34114657 .172763994$. 1517148794-396171367.1516104333. 
15. Rees CJ, Bevan R. The national health service bowel cancer screening program: the early years. Expert Rev Gastroenterol Hepatol 2013;7:421437.

16. Rex DK, Johnson DA, Anderson JC, Schoenfeld PS, Burke CA, Inadomi JM. American college of gastroenterology guidelines for colorectal cancer screening 2009 [corrected]. Am J Gastroenterol 2009;104:739-750.

17. Schreuders EH, Ruco A, Rabeneck L, et al. Colorectal cancer screening: a global overview of existing programmes. Gut 2015;64:1637-1649.

18. Cairns SR, Scholefield JH, Steele RJ, et al. Guidelines for colorectal cancer screening and surveillance in moderate and high risk groups (update from 2002). Gut 2010;59:666-689.

19. Rex DK, Bond JH, Winawer S, et al. Quality in the technical performance of colonoscopy and the continuous quality improvement process for colonoscopy: recommendations of the U.S. multi-society task force on colorectal cancer. Am J Gastroenterol 2002;97:1296-1308.

20. U.S. Preventive Services Task Force. Screening for colorectal cancer: U.S. preventive services task force recommendation statement. Ann Intern Med 2008;149:627-637.

21. Fletcher RH. Diet for fecal occult blood test screening: help or harm? Eff Clin Pract 2001;4:180-182.

22. Rabeneck L, Rumble RB, Thompson F, et al. Fecal immunochemical tests compared with guaiac fecal occult blood tests for population-based colorectal cancer screening. Can J Gastroenterol 2012;26:131-147.

23. Hewitson P, Glasziou P, Irwig L, Towler B, Watson E. Screening for colorectal cancer using the faecal occult blood test, Hemoccult. Cochrane Database Syst Rev 2007;(1):CD001216.

24. Hardcastle JD, Chamberlain JO, Robinson MH, et al. Randomised controlled trial of faecal-occult-blood screening for colorectal cancer. Lancet 1996;348:1472-1477.

25. Kronborg O, Fenger C, Olsen J, Jørgensen OD, Søndergaard O. Randomised study of screening for colorectal cancer with faecal-occult-blood test. Lancet 1996;348:1467-1471.

26. Mandel JS, Church TR, Ederer F, Bond JH. Colorectal cancer mortality: effectiveness of biennial screening for fecal occult blood. J Natl Cancer Inst 1999;91:434-437.

27. Kewenter J, Brevinge H, Engarås B, Haglind E, Ahrén C. Results of screening, rescreening, and follow-up in a prospective randomized study for detection of colorectal cancer by fecal occult blood testing. Results for 68,308 subjects. Scand J Gastroenterol 1994;29:468-473.

28. Logan RF, Patnick J, Nickerson C, Coleman L, Rutter MD, von Wagner C. Outcomes of the bowel cancer screening programme (BCSP) in England after the first 1 million tests. Gut 2012;61:1439-1446.

29. Leuraud K, Jezewski-Serra D, Viguier J, Salines E. Colorectal cancer screening by guaiac faecal occult blood test in France: Evaluation of the programme two years after launching. Cancer Epidemiol 2013;37:959967.

30. Pitkäniem J, Seppä K, Hakama M, et al. Effectiveness of screening for colorectal cancer with a faecal occult-blood test, in Finland. BMJ Open Gastroenterol 2015;2:e000034.

31. Paimela H, Malila N, Palva T, Hakulinen T, Vertio H, Järvinen H. Early detection of colorectal cancer with faecal occult blood test screening. $\mathrm{Br}$ J Surg 2010;97:1567-1571.

32. Steele RJ, McClements PL, Libby G, et al. Results from the first three rounds of the Scottish demonstration pilot of FOBT screening for colorectal cancer. Gut 2009;58:530-535.

33. Malila N, Anttila A, Hakama M. Colorectal cancer screening in Finland: details of the national screening programme implemented in Autumn 2004. J Med Screen 2005;12:28-32.

34. Katičić M, Antoljak N, Kujundžić M, et al. Results of national colorectal cancer screening program in Croatia (2007-2011). World J Gastroenterol 2012;18:4300-4307.

35. Geraghty J, Butler P, Seaman H, et al. Optimising faecal occult blood screening:retrospective analysis of NHS bowel cancer screening data to improve the screening algorithm. Br J Cancer 2014;111:2156-2162.

36. Holme Ø, Bretthauer M, Fretheim A, Odgaard-Jensen J, Hoff G. Flexible sigmoidoscopy versus faecal occult blood testing for colorectal cancer screening in asymptomatic individuals. Cochrane Database Syst Rev 2013;(9):CD009259.

37. Bretthauer M. Colorectal cancer screening. J Intern Med 2011;270:87-98.

38. von Wagner $\mathrm{C}$, Baio $\mathrm{G}$, Raine $\mathrm{R}$, et al. Inequalities in participation in an organized national colorectal cancer screening programme: results from the first 2.6 million invitations in England. Int J Epidemiol 2011;40:712718.

39. Palmer CK, Thomas MC, von Wagner C, Raine R. Reasons for non-uptake and subsequent participation in the NHS bowel cancer screening programme: a qualitative study. Br J Cancer 2014;110:1705-1711.

40. Bradley DT, Treanor C, McMullan C, Owen T, Graham A, Anderson D. Reasons for non-participation in the Northern Ireland bowel cancer screening programme: a qualitative study. BMJ Open 2015;5:e008266.

41. Levin B, Brooks D, Smith RA, Stone A. Emerging technologies in screening for colorectal cancer: CT colonography, immunochemical fecal occult blood tests, and stool screening using molecular markers. CA Cancer J Clin 2003;53:44-55.

42. Steele RJ, McDonald PJ, Digby J, et al. Clinical outcomes using a faecal immunochemical test for haemoglobin as a first-line test in a national programme constrained by colonoscopy capacity. United European Gastroenterol J 2013;1:198-205.

43. Lee JK, Liles EG, Bent S, Levin TR, Corley DA. Accuracy of fecal immunochemical tests for colorectal cancer: systematic review and meta-analysis. Ann Intern Med 2014;160:171.

44. Kapidzic A, van Roon AH, van Leerdam ME, et al. Attendance and diagnostic yield of repeated two-sample faecal immunochemical test screening for colorectal cancer. Gut 2017;66:118-123.

45. Hol L, Wilschut JA, van Ballegooijen M, et al. Screening for colorectal cancer: random comparison of guaiac and immunochemical faecal occult blood testing at different cut-off levels. Br J Cancer 2009;100:11031110.

46. Haug U, Grobbee EJ, Lansdorp-Vogelaar I, Spaander MCW, Kuipers EJ. Immunochemical faecal occult blood testing to screen for colorectal cancer: can the screening interval be extended? Gut 2017;66:1262-1267.

47. Allison JE, Fraser CG, Halloran SP, Young GP. Comparing fecal immunochemical tests: improved standardization is needed. Gastroenterology 2012;142:422-424.

48. van Rossum LG, van Rijn AF, Laheij RJ, et al. Random comparison of guaiac and immunochemical fecal occult blood tests for colorectal cancer in a screening population. Gastroenterology 2008;135:82-90.

49. Hol L, van Leerdam ME, van Ballegooijen M, et al. Screening for colorectal cancer: randomised trial comparing guaiac-based and immunochemical faecal occult blood testing and flexible sigmoidoscopy. Gut 2010;59:62-68.

50. Holme Ø, Løberg M, Kalager M, et al. Effect of flexible sigmoidoscopy screening on colorectal cancer incidence and mortality: a randomized clinical trial. JAMA 2014;312:606-615.

51. Schreuders EH, Grobbee EJ, Spaander MC, Kuipers EJ. Advances in fecal tests for colorectal cancer screening. Curr Treat Options Gastroenterol 2016;14:152-162.

52. Atkin WS, Edwards R, Kralj-Hans I, et al. Once-only flexible sigmoidoscopy screening in prevention of colorectal cancer: a multicentre randomised controlled trial. Lancet 2010;375:1624-1633.

53. Hoff G, Grotmol T, Skovlund E, Bretthauer M; Norwegian Colorectal Cancer Prevention Study Group. Risk of colorectal cancer seven years after flexible sigmoidoscopy screening: randomised controlled trial. BMJ 2009;338:b1846.

54. Segnan N, Armaroli P, Bonelli L, et al. Once-only sigmoidoscopy in colorectal cancer screening: follow-up findings of the Italian randomized controlled trial--SCORE. J Natl Cancer Inst 2011;103:1310-1322.

55. Schoen RE, Pinsky PF, Weissfeld JL, et al. Colorectal-cancer incidence and mortality with screening flexible sigmoidoscopy. N Engl J Med 2012;366:2345-2357.

56. Atkin WS, Cook CF, Cuzick J, Edwards R, Northover JM, Wardle J. 
Single flexible sigmoidoscopy screening to prevent colorectal cancer: baseline findings of a UK multicentre randomised trial. Lancet 2002;359:1291-1300.

57. Gondal G, Grotmol T, Hofstad B, Bretthauer M, Eide TJ, Hoff G. The Norwegian colorectal cancer prevention (NORCCAP) screening study: baseline findings and implementations for clinical work-up in age groups 50-64 years. Scand J Gastroenterol 2003;38:635-642.

58. Brenner H, Stock C, Hoffmeister M. Effect of screening sigmoidoscopy and screening colonoscopy on colorectal cancer incidence and mortality: systematic review and meta-analysis of randomised controlled trials and observational studies. BMJ 2014;348:g2467.

59. Holme $\varnothing$, Schoen RE, Senore C, et al. Effectiveness of flexible sigmoidoscopy screening in men and women and different age groups: pooled analysis of randomised trials. BMJ 2017;356:6673.

60. Atkin W, Wooldrage K, Parkin DM, et al. Long term effects of once-only flexible sigmoidoscopy screening after 17 years of follow-up: the UK flexible sigmoidoscopy screening randomised controlled trial. Lancet 2017;389:1299-1311.

61. Bevan R, Rubin G, Sofianopoulou E, Patnick J, Rees CJ. Implementing a national flexible sigmoidoscopy screening program: results of the English early pilot. Endoscopy 2015;47:225-231.

62. Neilson LJ, Bevan R, Nickerson C, et al. Bowelscope- results from the pilot sites. Gut;64(Suppl 1):A370.

63. Tang V, Boscardin WJ, Stijacic-Cenzer I, Lee SJ. Time to benefit for colorectal cancer screening: survival meta-analysis of flexible sigmoidoscopy trials. BMJ 2015;350:h1662.

64. Segnan N, Senore C, Andreoni B, et al. Baseline findings of the Italian multicenter randomized controlled trial of "once-only sigmoidoscopy"--SCORE. J Natl Cancer Inst 2002;94:1763-1772.

65. Masseria C. Colorectal cancer in Italy: a review of current national and regional practice on screening and treatment. Eur J Health Econ 2010;10 Suppl 1:S41-S49.

66. Moss S, Mathews C, Day TJ, et al. Increased uptake and improved outcomes of bowel cancer screening with a faecal immunochemical test: results from a pilot study within the national screening programme in England. Gut 2017;66:1631-1644.

67. von Wagner C, Bowyer H, Rees CJ, Atkin W, Wardle J. Patient-reported experience of comfort and dignity in flexible sigmoidoscopy: data from the NHS bowel scope screening pilot. Gut 2014;63(Suppl 1):A137.

68. Morris EJ, Rutter MD, Finan PJ, Thomas JD, Valori R. Post-colonoscopy colorectal cancer (PCCRC) rates vary considerably depending on the method used to calculate them: a retrospective observational population-based study of PCCRC in the English national health service. Gut 2015;64:1248-1256.

69. Corley DA, Jensen CD, Marks AR, et al. Adenoma detection rate and risk of colorectal cancer and death. N Engl J Med 2014;370:1298-1306.

70. Kaminski MF, Regula J, Kraszewska E, et al. Quality indicators for colonoscopy and the risk of interval cancer. N Engl J Med 2010;362:17951803.

71. Bowles CJ, Leicester R, Romaya C, Swarbrick E, Williams CB, Epstein O. A prospective study of colonoscopy practice in the UK today: are we adequately prepared for national colorectal cancer screening tomorrow? Gut 2004;53:277-283.

72. Lee TJ, Rutter MD, Blanks RG, et al. Colonoscopy quality measures: experience from the NHS bowel cancer screening programme. Gut 2012;61:1050-1057.

73. Regula J, Zagorowicz E, Butruk E. Implementation of a national colorectal cancer screening program. Curr Colorectal Cancer Rep 2006;2:25-29.

74. Kaminski MF, Kraszewska E, Rupinski M, Laskowska M, Wieszczy P, Regula J. Design of the polish colonoscopy screening program: a randomized health services study. Endoscopy 2015;47:1144-1150.

75. Quintero E, Castells A, Bujanda L, et al. Colonoscopy versus fecal immunochemical testing in colorectal-cancer screening. $\mathrm{N}$ Engl J Med 2012;366:697-706.

76. Kaminski MF, Bretthauer M, Zauber AG, et al. The NordICC study: rationale and design of a randomized trial on colonoscopy screening for colorectal cancer. Endoscopy 2012;44:695-702.

77. Winawer SJ, Zauber AG, Ho MN, et al. Prevention of colorectal cancer by colonoscopic polypectomy. N Engl J Med 1993;329:1977-1981.

78. Citarda F, Tomaselli G, Capocaccia R, Barcherini S, Crespi M. Efficacy in standard clinical practice of colonoscopic polypectomy in reducing colorectal cancer incidence. Gut 2001;48:812-815.

79. Tappenden P, Chilcott J, Eggington S, Patnick J, Sakai H, Karnon J. Option appraisal of population-based colorectal cancer screening programmes in England. Gut 2007;56:677-684.

80. Rutter MD, Nickerson C, Rees CJ, Patnick J, Blanks RG. Risk factors for adverse events related to polypectomy in the English bowel cancer screening programme. Endoscopy 2014;46:90-97.

81. Bevan R, Nickerson C, Patnick J, et al. Bowelscope: early results from the pilot sites. Gut 2014;63(Suppl 1):A145.

82. Ghanouni A, Plumb A, Rees CJ, et al. Patients' experience of colonoscopy in the English bowel cancer screening programme. Gut 2014;63(Suppl 1):A137-A138.

83. Plumb AA, Ghanouni A, Rees CJ, et al. Comparison of patient experience of colonoscopy and CT colonography in the English bowel cancer screening programme. Gut 2014;63(Suppl 1):A136-A137.

84. Spada C, Hassan C, Galmiche JP, et al. Colon capsule endoscopy: European society of gastrointestinal endoscopy (ESGE) guideline. Endoscopy 2012;44:527-536.

85. Spada C, Hassan C, Marmo R, et al. Meta-analysis shows colon capsule endoscopy is effective in detecting colorectal polyps. Clin Gastroenterol Hepatol 2010;8:516-522.

86. Rokkas T, Papaxoinis K, Triantafyllou K, Ladas SD. A meta-analysis evaluating the accuracy of colon capsule endoscopy in detecting colon polyps. Gastrointest Endosc 2010;71:792-798.

87. Sacher-Huvelin S, Coron E, Gaudric M, et al. Colon capsule endoscopy vs. colonoscopy in patients at average or increased risk of colorectal cancer. Aliment Pharmacol Ther 2010;32:1145-1153.

88. Triantafyllou K, Viazis N, Tsibouris P, et al. Colon capsule endoscopy is feasible to perform after incomplete colonoscopy and guides further workup in clinical practice. Gastrointest Endosc 2014;79:307-316.

89. Groth S, Krause H, Behrendt R, et al. Capsule colonoscopy increases uptake of colorectal cancer screening. BMC Gastroenterol 2012;12:80.

90. Alberti LR, Garcia DP, Coelho DL, De Lima DC, Petroianu A. How to improve colon cancer screening rates. World J Gastrointest Oncol 2015;7:484-491.

91. Halligan S, Wooldrage K, Dadswell E, et al. Computed tomographic colonography versus barium enema for diagnosis of colorectal cancer or large polyps in symptomatic patients (SIGGAR): a multicentre randomised trial. Lancet 2013;381:1185-1193.

92. von Wagner C, Smith S, Halligan S, et al. Patient acceptability of CT colonography compared with double contrast barium enema: results from a multicentre randomised controlled trial of symptomatic patients. Eur Radiol 2011;21:2046-2055.

93. von Wagner C, Ghanouni A, Halligan S, et al. Patient acceptability and psychologic consequences of CT colonography compared with those of colonoscopy: results from a multicenter randomized controlled trial of symptomatic patients. Radiology 2012;263:723-731.

94. Lin OS, Kozarek RA, Gluck M, et al. Preference for colonoscopy versus computerized tomographic colonography: a systematic review and meta-analysis of observational studies. J Gen Intern Med 2012;27:13491360.

95. Tappenden P, Eggington S, Richard Nixon R, Chilcott J, Sakai H, Karnon J. Colorectal cancer screening options appraisal: cost-effectiveness, cost-utility and resource impact of alternative screening options for colorectal cancer [Internet]. Sheffield: The University of Sheffield; c2004 [updated 2004 Sep; cited 2017 Sep 5]. Available from: https://pdfs.semanticscholar.org/09a0/8003b99c2abaf7d49308229a72ddfe54f677.pdf.

96. Zauber AG, Lansdorp-Vogelaar I, Knudsen AB, Wilschut J, van Ballegooijen M, Kuntz KM. Evaluating test strategies for colorectal cancer 
screening-age to begin, age to stop, and timing of screening intervals. Rockville (MD): Agency for Healthcare Research and Quality (US); 2009.

97. Zauber AG, Knudsen AB, Carolyn R, et al. Evaluating the benefits and harms of colorectal cancer screening strategies: a collaborative modeling approach to inform the US preventive services task force. Gastroenterology 2016;150(4 Suppl 1):S46.

98. U.S. Preventive Services Task Force. Draft evidence review for colorectal cancer: screening [Internet]. Rockville (MD): U.S. Preventive Services Task Force; c2015 [updated 2015 Oct; cited 2017 Sep 5]. Available from: https://www.uspreventiveservicestaskforce.org/Page/Document/ draft-evidence-review54/colorectal-cancer-screening2.
99. Harewood GC, Lawlor GO, Larson MV. Incident rates of colonic neoplasia in older patients: when should we stop screening? J Gastroenterol Hepatol 2006;21:1021-1025.

100. Brenner H. Colorectal cancer screening for older adults. BMJ 2015;350:h2029.

101. Qaseem A, Denberg TD, Hopkins RH Jr, et al. Screening for colorectal cancer: a guidance statement from the American college of physicians. Ann Intern Med 2012;156:378-386.

102. Winawer SJ, Zauber AG, Fletcher RH, et al. Guidelines for colonoscopy surveillance after polypectomy: a consensus update by the US multi-society task force on colorectal cancer and the American cancer society. Gastroenterology 2006;130:1872-1885. 